\title{
HUBUNGAN STRES KERJA DENGAN PERFORMA KERJA DIMODERASI MOTIVASI BERPRESTASI PADA ANGGOTA POLRES BLITAR
}

\author{
Yuyus Aditya Pratama*, Iswinarti, Rr. Siti Suminarti Fasikhah
}

\section{${ }^{*}$ Corresponding Author:}

Magister Psikologi

Universitas Muhammadyah Malang

Email:

yuyusblitar09@gmail.com

\begin{abstract}
Abstrak. Penelitian ini bertujuan untuk menganalisis hubungan stres kerja dengan performa kerja yang dimoderasi oleh motivasi berprestasi. Desain penelitian ini adalah penelitian kuantitatif korelasional. Penentuan subjek menggunakan accidental sampling. Subjek penelitian ini adalah anggota Polres Blitar yang berjumlah 341 orang dengan sampel 150 orang. Skala yang digunakan untuk mengukur stress adalah New Job Stress Scale, skala untuk mengukur performa kerja Individual Work Performance Questionare Performa kerja anggota Kepolisian menentukan baik dan buruknya kualitas pelayanan terhadap masyarakat. Dalam menjalankan tugas, anggota kepolisian perlu mengelola stres kerja sehingga dapat mencapai performa kerja yang diinginkan, dan dalam mengukur motivasi berprestasi menggunakan Teori Mcclelland dengan skala motivasi berprestasi. Analisa data yang digunakan dalam penelitian ini adalah analisis Hayes. Berdasarkan hasil analisis menunjukkan adanya hubungan positif dan signifikan antara stres kerja dengan performa kerja. Dari hasil analisis pada ketiga variabel diambil keputusan $\beta=0.616$ dengan $\mathrm{p}=0.00$, motivasi berprestasi memoderasi hubungan stres kerja dengan performa kerja.
\end{abstract}

Kata kunci: Stres Kerja, Performa Kerja, Motivasi Berprestasi

\begin{abstract}
This study aims to analyze the relationship between work stress and work performance which is moderated by achievement motivation. The design of this research is correlational quantitative research. Determination of the subject using accidental sampling. The subjects of this study were 341 Blitar police officers with a sample of 150 people. The scale used to measure stress is the New Job Stress Scale, a scale to measure the work performance of the Individual Work Performance Questionnaire The work performance of members of the Police determines the good and bad quality of service to the community. In carrying out their duties, police officers need to manage work stress so that they can achieve the desired work performance, and in measuring achievement motivation using the Mcclelland Theory with achievement motivation scale. Analysis of the data used in this study is Hayes analysis. Based on the results of the analysis showed a positive and significant relationship between work stress and work performance. From the results of the analysis of the three variables, the decision $\beta=0.616$ with $p=0.00$ was made, achievement motivation moderates the relationship between work stress and work performance.
\end{abstract}

Keywords: Job Stress, Work Performance, Achievement Motivation

\section{PENDAHULUAN}

Performa kerja dipengaruhi oleh faktor eksternal maupun internal, salah satu faktor internalnya adalah stres (Abu Al Rub, 2004). Keberhasilan sebuah organisasi sangat bergantung pada kinerja pegawainya. Keberadaan anggota Kepolisian, sebagai aparat penegak hukum dituntut untuk bekerja secara legalitas, pro- porsionalitas, profesionalitas, reasonable, efektif dan efisien dalam rangka memaksimalkan tugas pokok, fungsi dan peran organisasi Kepolisian. Selain tuntutan tersebut tanggungjawab yang lain adalah menjaga dan memperbaiki citra para anggota dimata masyarakat, sehingga keadaan yang ada di Kepolisian harus berusaha meningkatkan kinerja anggotanya agar 
tujuan organisasi dapat dicapai dengan efektif dan efisien. Kinerja anggota Kepolisian dapat dikaji dengan melihat faktor yang mempengaruhi kinerja anggota, bahkan dapat dikatakan sangat menentukan dalam usaha pencapaian tujuan organisasi yang sudah ditetapkan.

Stres mempengaruhi performa kerja, jika orang terindikasi mengalami stres maka akan mengurangi performa dikarenakan orang tersebut bisa jadi mengalami kelelahan, tidak fokus, mengantuk, kurang fit, tidak semangat. Stres kerja menurut Robbins (2006) yaitu kondisi dinamik yang di dalamnya ada kendala, atau tuntutan yang terkait dengan apa yang sangat diinginkan dan hasil yang dipersepsikan sebagai tidak pasti tetapi penting.

Stres kerja adalah kondisi yang muncul akibat ketidak cocokan antara pegawai dan lingkungan kerjanya yang mengancam kesejahteraan dari pegawai tersebut (Beehr \& Newman, 1978). Stres kerja pada Polisi penting untuk diperhatikan karena menurut Schaufeli dan Enzman (Euwema, Kop \& Bakker, 2004) stres kerja pada profesi polisi berdampak buruk terhadap kualitas hubungan antara Polisi dan masyarakat, sementara inti dari tugas menjadi seorang polisi adalah berhubungan dengan masyarakat, pada kondisi stres anggota Polisi menggunakan kata-kata atau perilaku kasar pada saat berinteraksi dengan masyarakat

Stres kerja muncul akibat tuntutan pekerjaan yang tidak seimbang dengan kemampuan seseorang. Stres kerja dapat memengaruhi efektivitas kinerja seseorang dan dapat menghambat seseorang dalam menunjukkan performa kerja yang maksimal. Stres merupakan segala masalah atau tuntutan penyesuaian diri. Stres kerja yang terjadi dapat menimbulkan dampak secara langsung maupun tidak langsung terhadap aspek fisik, psikologis maupun perilaku. Setiap orang dalam kekuatan untuk bisa bertahan terhadap stres atau nilai ambang frustasi stres itu berbeda-beda.

Pekerjaan polisi masuk dalam deretan pekerjaan yang paling membuat stres di Amerika (Adicio, 2017). Pada tahun 2014, pekerjaan polisi menempati posisi ke 9 dari 10 pekerjaan lainnya yang membuat stres. Tahun 2015, meningkat menjadi posisi ke 5 dan pada tahun selanjutnya pekerjaan polisi masih berada pada posisi yang sama. Kesepuluh pekerjaan tersebut meliputi petugas pemadam kebakaran, calon personil militer, tentara, pilot pesawat, polisi, koordinator acara, reporter koran, eksekutif perusahaan (senior), public relation executive, dan sopir taxi. Pekerjaan tersebut membutuhkan orang-orang yang bisa berhadapan dengan kondisi yang tidak dapat terprediksi, juga dekat dengan sesuatu yang berbahaya, hingga situasi yang mengharuskan mereka untuk mempertaruhkan hidup (www.careercast.com). Setiap orang memiliki tingkat penyesuaian diri terhadap stres yang berbeda-beda. Hal itu disebabkan masing-masing orang memilki perbedaan atau tuntutan hidup dalam sehari-hari (Desima, 2013).

Stres kerja yang dialami anggota Polres Blitar di antaranya adanya jarak komunikasi komandan dengan para anggota terasa begitu jauh karena perbedaan strata atau budaya hirarki (senioritas), mayoritas pimpinan dan sebaliknya sulit bergaul bahkan sekedar bercengkrama, sehingga secara interpersonal hubugan antara atasan dengan bawahan memiliki jarak. Tanpa memahami kondisi bawahan yang sudah berusaha bekerja dengan baik dan permasalahan pribadi yang mereka alami setiap harinya terkadang menyulitkan beberapa anggota tersebut untuk selalu terlihat profesional ketika bekerja. Selain itu pada lingkup administratif ada beberapa anggota pula menjelaskan jika pekerjaan yang lebih sedikit mengalami kelelahan dan stres itu berada pada anggota yang ditempatkan di bagian administratif daripada anggota yang harus dijalani setiap hari untuk terjun ke lapangan secara langsung. Ada pula kebalikannya, anggota yang ditempatkan di bagian administratif menceritakan bahwa anggota tersebut sering mengalami kejenuhan tentang pekerjaan yang kurang menantang, dan bagi dirinya ada pekerjaan di lapangan yang bisa membuat hidup menjadi lebih terasa sebagai seorang pelindung, pengayom dan pelayan.

Motivasi sangat diperlukan pada anggota kepolisian untuk membuat para personil lebih giat dalam melakukan pekerjaannya. Motivasi merupakan suatu aktivitas yang menempatkan seseorang atau kelompok yang mempunyai kebutuhan tertentu dan pribadi, untuk bekerja menyelesaikan tugasnya. Selain itu motivasi merupakan kekuatan, dorongan, kebutuhan, tekanan dan mekanisme psikologis yang dimaksudkan merupakan akumulasi faktor-faktor internal (berasal dari individu seperti kepribadian) dan eksternal (berasal dari lingkungan fisik maupun sosial). Motivasi juga sebagai suatu proses dimana kebutuhan- kebutuhan mendorong seseorang untuk melakukan serangkaian kegiatan yang mengarah ke tercapainya tujuan tertentu. Tujuan yang jika berhasil dicapai, maka akan memuaskan atau memenuhi kebutuhan-kebutuhan tersebut (Munandar, 2014).

Motivasi berprestasi menjadi sangat penting karena melalui motivasi seseorang terdorong untuk melakukan suatu pekerjaan (Anoraga 2006). Motivasi berprestasi merupakan modal untuk meraih kesuksesan, dan merupakan suatu daya dalam mental manusia untuk melakukan suatu kegiatan yang 
lebih baik, lebih cepat, lebih efektif, dan lebih efisien daripada kegiatan yang dilakukan sebelumnya. Motivasi berprestasi merupakan suatu unsur terpenting sebagai faktor untuk mendorong meraih keinginan untuk mencapai kesuksesan dan keberhasilan. Motivasi sangat mutlak dibutuhkan dalam kehidupan seseorang, tanpa motivasi kehidupan tidak mempunyai arah dan tujuan. Karyawan merasa bangga ketika mempunyai prestasi yang bisa dibanggakan sehingga karyawan membutuhkan motivasi berprestasi. Karyawan yang memiliki motivasi berprestasi yang tinggi menyebabkan karyawan selalu timbul kesadaran bahwa dorongan dalam meraih kesuksesan dapat melekat pada sikap dan menjadi perilaku permanen pada karyawan.

Kuatnya motivasi yang dimiliki individu akan banyak menentukan terhadap kualitas perilaku yang ditampil-kannya, baik dalam konteks belajar, bekerja maupun dalam kehidupan lainnya. Seorang anggota yang tidak termotivasi, hanya melakukan upaya minimum dalam memberikan pelayanan di bidang pekerjaannya. Sementara mereka yang memiliki motivasi kuat dan tinggi menurut Rahmila (2012), akan menciptakan sebuah komitmen terhadap apa yang menjadi tanggung jawabnya dalam menyelesaikan pekerjaannya. Disitu dikatakan pula bahwa dengan adanya motivasi berprestasi yang tinggi dapat meningkatkan produktifitas karyawan.

Beberapa penelitian terdahulu yang berkaitan dengan stres kerja, performa kerja dan motivasi berprestasi telah dilakukan di antaranya adalah Yozgat et al. (2013) yang menunjukkan bahwa stres kerja memiliki hubungan negatif terhadap performa kerja. Kecerdasan emosional memiliki dampak positif terhadap performa kerja. Sebelumnya juga ada penelitian oleh Ali et al. (2013) yang menunjukkan bahwa stres kerja memiliki hubungan dengan performa kerja. Selanjutnya penelitian Zafar et al. (2015) menunjukkan bahwa stres kerja berpengaruh positif terhadap kinerja.

Berdasarkan latar belakang tersebut, dan adanya perbedaan hasil penelitian tersebut, sehingga peneliti tertarik untuk melakukan penelitian, maka dirumuskan permasalahan sebagai berikut: Bagaimana hubungan stres dengan performa kerja yang dimoderasi motivasi berprestasi pada anggota Polres Blitar. Tujuan penelitian adalah menganalisis hubungan stres dengan performa kerja dimoderasi motivasi berprestasi pada anggota Polres Blitar. Penelitian ini diharap dapat menambah kajian ilmu dalam psikologi industri organisasi, dan secara praktis dapat menjadi rujukan bagi instansi organisasi untuk memperhatikan faktor stres dalam mengelola sumber daya manu- sia khususnya dalam meningkatkan performa kerja.

\section{METODE PENELITIAN Desain Penelitian}

Penelitian ini menggunakan pendekatan kuantitatif dengan desain penelitian kuntitatif korelasional yang termasuk dalam ex-post facto. Dalam penelitian ex-post facto tidak ada kelompok kontrol atau kegiatan pre tes. Hubungan sebab dan akibat antara subjek satu dengan subjek yang lain diteliti tidak manipulasi, karena penelitian ex- post facto hanya mengungkap gejala-gejala yang ada atau telah terjadi. Fakta dalam penelitian ini diungkapkan apa adanya dari data yang terkumpul. Dengan demikian penelitian ini mengungkapkan hubungan dari variabel-variabel yang ada.

\section{Subjek Penelitian}

Populasi penelitian ini seluruh anggota Kepolisian Resort Blitar Kabupaten yang berjenis kelamin laki-laki berjumlah 341 Polisi, sedangkan jumlah sampel penelitian diambil sebanyak 150 orang dengan kriteria kepangkatan tingkat bintara, usia 24 sampai 45 tahun, dan status sudah menikah. Pengambilan sampel menggunakan accidental sampling, seluruh sampel merupakan anggota Polres Blitar.

\section{Instrumen Penelitian}

Stress kerja diukur menggunakan the new job stress scale (Shukla \& Srivastava, 2016) dengan 5 aspek utama yaitu: job stress 16 item, role ekspectation conflict 3 item, cow worker support 3 item, dan work life balance 3 item serta cornbachs alpha 0,92. Terdapat 5 pilihan jawaban yaitu sangat tidak setuju, 2. tidak setuju, 3. bimbang, 4. setuju, 5. sangat tidak setuju

Performa kerja diukur menggunakan individual work performance questionnaire (IWPQ) (Koopmans et al., 2012), mengukur 3 aspek utama yaitu task performance, conceptual performance, dan adaptif performance. Skala ini sudah diuji oleh Prawira (2018) dengan jumlah item sebanyak 8 item, Cronbach alpha sebesar 0,84 . Dengan pembagian 4 item task performance, 2 item conceptuals, dan 2 item adaptif performance. Terdapat 4 pilihan jawaban 1 Sangat tidak sesuai, 2. Tidak sesuai, 3. Sesuai, 4 . Sangat tidak sesuai

Motivasi berprestasi diukur dengan menggunakan 5 indikator sesuai dengan teori Mc clelland. Skala yang digunakan dalam motivasi berprestasi sudah diuji oleh Hestisani (2014) dengan Cronbach alpha sebesar 0,75 . Indikatornya meliputi 1) memiliki tanggung jawab dan keuletan untuk melakukan semua tugasnya dengan sebaik-baiknya, 2) menyukai tantangan dan berusaha untuk mengatasi tantangan 
tersebut, 3) mengharapkan adanya umpan balik yang konkrit untuk menentukan tindakan yang lebih efektif untuk mencapai prestasi 4) memiliki tujuan yang realistis dan sesuai dengan kemampuannya, 5) mempertimbangkan resiko yang harus dihadapinya. Terdapat 5 pilihan jawaban yaitu 1. sangat tidak setuju, 2. tidak setuju, 3 . bimbang, 4 . setuju, 5. sangat tidak setuju

\section{Analisis Data}

Dalam penelitian ini, uji hipotesa yang dilakukan dengan menggunakan model analisis data Process dari Hayes, yang tujuannya untuk menguji pengaruh variabel (M) dalam memediasi hubungan antara Stres (X) terhadap Performa Kerja (Y). (Hayes, 2014).

\section{HASIL DAN PEMBAHASAN}

\section{Hasil}

Uji Hipotesis

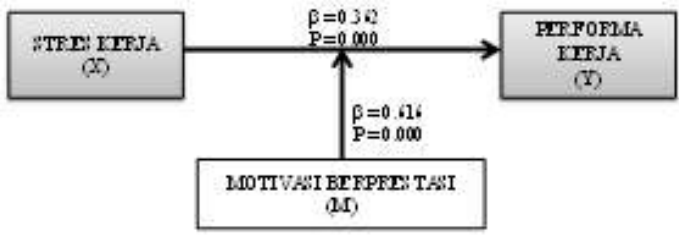

Gambar 1. Hasil analisis interaksi hubungan ketiga variabel

\section{Hubungan Stres Kerja dengan Performa Kerja}

Berdasarkan hasil analisis data yang telah dilakukan menunjukkan bahwa $\mathrm{H} 1$ diterima. Dilihat dari nilai $\beta=0.362$ dengan $p=0.000$, artinya terdapat hubungan positif dan signifikan antara stres kerja dengan performa kerja. Hal ini menunjukkan bahwa semakin tinggi stres kerja maka semakin tinggi performa kerja. Sebaliknya, semakin rendah stres kerja maka semakin rendah performa kerja.

\section{Hubungan Stres Kerja dan Performa Kerja dengan Motivasi Berprestaasi Sebagai Variabel Moderator}

Hipotesis kedua (H2) dalam penelitian ini adalah motivasi berprestasi memoderasi hubungan antara stres kerja dengan performa kerja. Dari hasil analisis pada ketiga variabel memperoleh nilai $\beta=0.616$ dengan $\mathrm{p}=0.000$, sehingga dapat dikatakan bahwa $\mathrm{H} 2$ diterima, artinya motivasi berprestasi memoderasi hubungan stres kerja dengan performa kerja.

Grafik pada gambar 2, dapat kita lihat bahwa pada subjek yang mempunyai motivasi berprestasi tinggi, cenderung diikuti dengan tingginya stres kerja dan tingginya performa kerja. Pada subjek dengan motivasi berprestasi rendah, cenderung mempunyai stres keria rendah dan performa keria yang rendah juga.

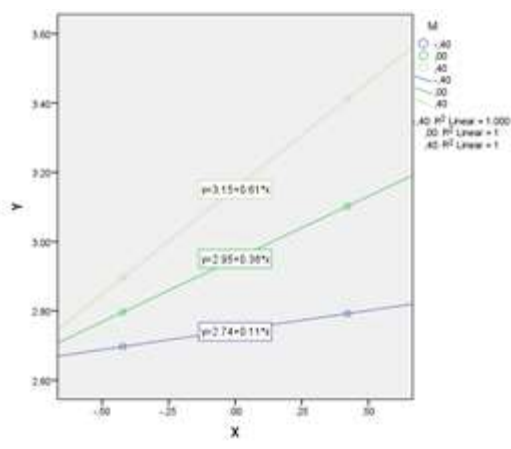

Gambar 2. Grafik Moderasi

\section{Pembahasan}

Dari hasil analisa data yang telah dilakukan, menghasilkan bahwa terdapat hubungan positif antara stres kerja dengan performa kerja dan motivasi berprestasi menjadi moderasi pada hubungan antara stres kerja dengan performa kerja. Stres kerja merupakan dampak yang ditimbulkan dari berbagai situasi serta kondisi lingkungan, baik internal maupun eksternal. Di mana sedikit banyak tiap karakteristik dari pekerjaan yang dilakukan membawa akibat pada performa kerja, apakah itu berakibat pada perilaku yang positif maupun negatif. Pada saat tertentu stres kerja memang diperlukan untuk memacu performa kerja Anggota Polres agar meningkat dan semakin kuat dalam menjalani hidup yang penuh dengan tantangan, mata akan semakin jeli untuk melihat tantangan yang akan datang, dan sudah mempunyai suatu pengalaman bagaimana untuk mengatasi hal tersebut. Hasil penelitian ini Yozgat et al. (2013) yang menunjukkan bahwa stres kerja memiliki hubungan dengan performa kerja. Hasil penelitian ini juga mendukung Zafar et al. (2015) yang menyatakan bahwa stres kerja berpengaruh terhadap kinerja.

Masalah Stres kerjai di dalam organisasi perusahaani menjadi gejalai yangi pentingi diamati sejak mulai timbulnyai tuntutani untuk efisiensi di dalam pekerjaan. Perusahaani harus memperhatikani stres kerjai karyawannya, karenai karyawani merupakani asset berhargai bagi perusahaani yangi merupakani faktor pentingi untuk mencapai tujuani suatu organisasi. Dalam hubungannyai dengani pekerjaan, setiap individu pasti pernah mengalami stress. Adakalanyai stres yangi dialami seseorangi itu adalah kecil dani hampir tberarti, namuni bagi yangi lainnyai dianggap sangat mengganggu dani berlanjut dalam waktu yangi relatif lama. Stres kerjai bisai menimbulkani dampak positif dani sekaligus negatif bagi individu dani bagi organisasi atau perusahaan. Stres dikatakani positif dani merupakani suatu peluangi bilai stres tersebut memotivasi parai karyawani untuk meningkatkani kinerjanyai agar memperoleh hasil yangi maksimal. 
Stres dikatakani negatif bilai stres memberikani hasil yangi menuruni padai produktifitas kerjai karyawan.

Reaksi terhadap stres dari waktu ke waktu dan terhadap perubahan intensitas stres, artinya stres tingkat sedang sekalipun dapat mempunyai pengaruh yang negatif pada performa kerja jangka panjang karena intensitas stres yang berkelanjutan itu meruntuhkan individu itu dan melemahkan sumber daya energinya. Tetapi stres tingkat sedang yang dialami terus menerus selama waktu yang panjang dapat mengakibatkan menurunnya performa kerja (Robbins, 2006). Beban kerja yang berlebihan mampu menimbulkan tekanan bagi anggota Polres sehingga dibutuhkan jam kerja yang jelas sebagai pendelegasian pekerjaan bagi anggota Polres sesuai dengan proporsinya. Namun bila anggota Polres mampu mengatur kembali pekerjaan yang telah dikerjakan, mampu mengatur kembali pekerjaan yang sedang dilakukan dan mampu mengatur kembali pekerjaan yang akan dilakukan dapat mengurangi beban kerja.

Wibowo (2014) mengemukakan stres kerja sebagai suatu kondisi ketegangan yang mempengaruhi proses berpikir, emosi, dan kondisi seseorang, hasilnya stres yang terlalu berlebihan dapat mengancam kemampuan seseorang untuk menghadapi lingkungan dan pada akhirnya akan mengganggu pelaksanaan tugas-tugasnya. Hasilnya stres yang terlalu besar dapat mengancam kemampuan seseorang untuk menghadapi lingkungan, yang akhirnya mengganggu pelaksanaan tugas-tugasnya, dan berarti mengganggu performa kerja.

Motivasi berprestasi mampu memoderasi hubungani stres kerjai dengani performai kerja. Motivasi berprestasi anggotai Polres dalam bekerjai yangi baik akani memberikani dampak positif, baik bagi diri individu maupuni pihak organisasi. Anggotai Polres dengani ciri-ciri motivasi berprestasi yangi tinggi akani memiliki keinginani bekerjai yangi tinggi, karenai selalu ingini mengerjakani sesuatu dengani lebih baik. Anggotai Polres lebih mementingkani kepuasani padai saat target telah tercapai dibandingkani imbalani atas performai kerjai tersebut. Hal ini bukani berarti anggotai Polres tidak mengharapkani imbalan, melainkani anggotai Polres menyukai tantangan. Anggotai Polres yangi mempunyai motivasi berprestasi yangi tinggi akani berusahai dengani sekuat tenagai agar pekerjaannyai dapat berhasil dengani sebaik-baiknya. Apabilai kebutuhani pribadinyai terpenuhi, makai anggotai Polres akani dapat bekerjai lebih giat.

Stres kerjai merupakani suatu gejalai yangi dimiliki oleh setiap orangi dimanai hal tersebut dipengaruhi diri sendiri maupuni lingkungani sekitar. Stres jugai terjadi dalam kerjai dimanai stres tersebut dapat bersumber dari empat hal yaitu tingkat individu, tingkat kelompok, tingkat organisasi dani ekstraorganisasional. Keempat hal tersebut dapat menghasilkani stres yangi berbedai padai setiap individu tergantungi bagaimanai individu itu meresponi stressor tersebut. Setelah adanyai responi barulah dapat ditentukani bagaimanai stres yangi dialami seseorangi tersebut. Stres yangi terjadi dapat berupai stres positif maupuni negatif dimanai stres itu akani memberikani dampak tersendiri bagi orangi yangi mengalami stres. Stres yangi dialami pekerjai tersebut masih dapat diatasi atau dikurangi dengani banyak metode sehinggai diperlukannyai suatu manajemeni stress dalam pekerjaani suatu perusahaan. Sertai adanyai usahai dari orangi tersebut untuk dapat mengurangi stres yangi dialami. Padai dasarnyai stress terjadi karenai terlalu beratnyai bebani pikirani seseorangi sertai adanyai tekanani yangi membuat kurangnyai konsentrasi. Namuni semuai itu masih dapat dicegah bahkani dimanajemeni untuk dapat mengurangi pengaruhnyai dalam bekerja.

Anggota Polres yang memiliki motivasi berprestasi akan melakukan pekerjaan dengan baik dan kinerja yang tinggi. Kebutuhan akan berprestasi tinggi merupakan suatu dorongan yang timbul pada diri seseorang untuk berupaya mencapai target yang telah ditetapkan, bekerja keras untuk mencapai keberhasilan dan memiliki keinginan untuk mengerjakan sesuatu secara lebih lebih baik dari sebelumnya. Anggota Polres dengan motivasi berprestasi tinggi sangat menyukai tantangan, berani mengambil risiko, sanggup mengambil alih tanggungjawab, senang bekerja keras. Dorongan ini akan menimbulkan kebutuhan berprestasi Anggota Polres yang membedakan dengan yang lain, karena selalu ingin mengerjakan sesuatu dengan lebih baik. Berdasarkan pengalamam dan antisipasi dari hasil yang menyenangkan serta jika prestasi sebelumnya dinilai baik, maka Anggota Polres lebih menyukai untuk terlibat dalam perilaku berprestasi. Sebaliknya jika Anggota Polres telah dihukum karena mengalami kegagalan, maka perasaan takut terhadap kegagalan akan berkembang dan menimbulkan dorongan untuk menghindarkan diri dari kegagalan.

\section{KESIMPULAN DAN SARAN \\ Kesimpulan}

Hasil analisis menunjukkan bahwa terdapat hubungan negatif antara stres kerja dengan performa kerja. Individu yang memiliki stres kerja yang tinggi dapat menurunkan performa kerja. Hasil yang kedua yaitu semakin tinggi motivasi berprestasi mengurangi hubungan stres kerja dengan performa kerja sebali- 
knya Semakin rendah motivasi berprestasi meningkatkan hubungan stress kerja dengan performa kerja sehingga disimpulkan motivasi berprestasi mampu memoderasi hubungan stres kerja dengan performa kerja.

\section{Saran}

Stres kerja dapat mengurangi konsentrasi seseorang, menurunkan performa kerja, peningkatan frekuensi kesalahan pada pekerjaan, tingginya tingkat cedera pada pekerjaan, tingginya tingkat absensi dan lekas marah serta meningkatkan konflik dengan rekan kerja. Stres meningkat ketika atasan atau rekan kerja secara sosial menjadi tidak sensitif terhadap kebutuhan orang lain atau merendahkan orang lain dan terlalu kritis terhadap pekerjaan yang dihasilkan oleh orang lain. Selain itu, anggota Polres akan mengalami stres jika anggota Polres merasakan tidak dihargai oleh orang lain atau merasa tidak mengalami kemajuan dalam pekerjaannya. Ditambah lagi jika anggota Polres tidak mendapatkan pengakuan atau promosi kerja dari instansi yang diyakini bahwa Anggota Polres layak mendapatkannya.

Dalam kaitannya dengan upaya meningkatkan performa kerja Anggota Polres, maka dibutuhkan adanya sejumlah motivasi berprestasi yang tinggi. Oleh karenanya motivasi berprestasi memiliki keterkaitan yang sangat erat terhadap performa kerja Anggota Polres. Pemberian motivasi berprestasi secara individu kepada Anggota Polres akan berjalan lebih cepat sehingga Anggota Polres dapat bekerja secara maksimal di polres Blitar. Motivasi berprestasi terbentuk dari sikap seorang Anggota Polres dalam menghadapi situasi kerja. Motivasi berprestasi merupakan kondisi yang menggerakkan diri Anggota Polres yang terarah untuk mencapai tujuan organisasi atau tujuan kerja.

Saran untuk Dinas Kepolisian Resort Blitar yang membidangi perencanaan dan pengembangan sumber daya manusia agar dapatnya memetakan tingkat stres kerja anggota Polres dengan secara berkala melakukan assesment NOA (Need Of Achievment) untuk mengetahui tingkat kemauan berprestasi dalam kaitanya dengan optimalisasi performa kerja. Selanjutnya salah satunya bisa dilakukan AMT (Achievment Motivation Training) terhadap anggota Polres dan bekerjasama dengan lembaga Psikologi dalam pelaksanaannya.

Untuk peneliti selanjutnya agar menggunakan variabel lain untuk mengetahui kemungkinan lain dari hubungan stres kerja dengan performa kerja misalnya variabel ketahanan kerja, subjektif wellbeing.

\section{DAFTAR PUSTAKA}

Abu Al Rub, R.F., (2004) Job stress, job performance and social support among hospital nurses. J. Nurs. Scholarsh., 36(1);73-78.

Ali, K, Ishtiaq, I dan Ahmad, M. (2013). Occupational stress effects and Job performance in the teachers of schools of punjab (Pakistan). International Journal of Academic Research in Business and Social Sciences. Vol 3. No. 11: 665-680.

Anoraga, Pandji. (2006). Psikologi Kerja. Jakarta: PT. Rineka Cipta

Beehr, T.a. \& Newman,J.E. (1978). Job stress. Employee health and organization Effectiveness : A Facet Analisis Model and Literature Review. Personel Psichology.

Belle (2012). Environmental psychology fourth edition. Harcourt Brace College Publishers

Campbell. J. P. (1990). Productivity in organizations. Josey-Bass Publishe. San Fransisco.

Campbell, J. P., dan Wiernik, B. M. (2015). The modeling and assessment of work performance. The Annual Review of Organizational Psychology and Organizational Behavior. 2;47-74.

Careercast.com (2016). The Most Stressful Jobs of 2016. http://www.careercast.com/jobs-rated/moststressful-jobs-2016. Diakses pada tanggal 28 April 2016

Chatab, Nevizond. 2007. Profil Budaya Organisasi. Bandung : Penerbit Alfabeta

Chukwuma, E.M., \& Obiefuna, O. (2014). Effect of Motivation on Employee Productivity : A Study of Manufacturing Companies in Nnewi. Journal of Managerial Studies and Research. 2 (7).

Dwiyanti. (2001). Stres Kerja di Lingkungan DPRD: Study tentang Anggota DPRD di kota Surabaya, Malang dan Kabupaten Jember. Jurnal Masyarakat, Kebudayaan dan politik. Surabaya: Fakultas Kesehatan Masyarakat Universitas Airlangga.

Euwema, M. C., Kop, N., \& Bakker, A. B. (2004). The behaviour of police officers in conflict situations: How burnout and reduced dominance contribute to better outcomes. In Work \& Stress (Vol. 18, Issue 1, pp. 23-38). Taylor \& Francis. https://doi. org/10.1080/0267837042000209767

Desima. (2013). Tingkat Stres Kerja Perawat Dengan Perilaku Caring Perawat. Journal Universitas $\mathrm{Mu}$ hammadiyah Malang. Vol (4) No. 1 Hal.43-55

Fauji, H. (2013). Pengaruh stres kerja dan konflik kerja terhadap semangat kerja karyawan di PT. Karya Mandiri Environment. Universitas Pasundan Badung.

Ghozali, I. (2007). Aplikasi analisis multivariate dengan program SPSS. Badan Penerbit Universitas 


\section{Diponegoro, Semarang}

Gujarati, Damodar N. 2006. Ekonometrika dasar. Jakarta : Penerbit Erlangga.

Hasibuan, M.Sp. (2012). Manajemen SDM. Edisi Revisi, Cetakan Ke Tigabelas. Jakarta : Bumi Aksara.

Hayes, A. F. (2014). Statistical mediation analysis with a multicategorical independent variable. British Journal of Mathematical and Statistical Psychology, 67(2), 451-470.

Hestisani, Hindria. 2014. Pengaruh Motivasi Berprestasi dan Disiplin Kerja terhadap Kinerja Pegawai pada Badan Kepegawaian Derah Kabupaten Buleleng. E-journal.

Hurtz, G.M., and Donovan, J.J. (2000). Personality and job performance: the big five revisited. Journal of Applied Psychology, 85 (6), 869-879.

Koopmans, et al. (2013). Improving the individual work performance questionnaire using rasch analysis. J Appl Meas, 15(2), 160-175.

Mahesa, D. (2010). Analisis Pengaruh Motivasi dan Kepuasan kerja Terhadap Kinerja Karyawan Dengan Lama Kerja Sebagai Variabel Moderating (Studi pada PT. Coca Cola Amatil Indonesia (Centaral Java)). Semarang: Universitas Diponegoro

Masa'Deh, R., \& Abusalem S. AbuRuz, M.E., Alaloul, F., Saifan, A., (2017). Quality of life for saudi patients with heart failure: A cross-sectional corelational study. Global Journal of Health Science, $8(3), 49-58$

Munandar. (2014). Psikologi industri dan oganisasi. Jakarta: Rineka Cipta

Miftahun dan Sugiyanto. (2010). Pengaruh dukungan social dan kepemimpinantransformasional terhadap komitmen organisasi dengan mediator motivasikerja. Jurnal Psikologi. volume 37, No. 1, $94-109$

Newstrom, J.W. (2011). Organizational Behavior Human Behavior. at Work (13rd) New York : McGraw-Hill

Pamela, A.O., \& Oloko (2015). Effect of motivation on employee performance of commercial banks in kenya : A case study of Kenya Commercial Bank in Migori County. Journal of Human Resource Studies. 5 (2)

Prawira, E. F. (2018). Pengaruh Affective commitment terhadap job performance dimediasi oleh meaningful work pada TNI angkatan darat. Thesis. Universitas Muhamadiyah Malang.

Robbins, S. (2008). Perilaku organisasi, Jilid I dan II, alih Bahasa: Hadyana Pujaatmaja. Jakarta: Prenhallindo.

Robbins, Stephen P. (2006). Perilaku organisasi. alih Bahasa : Hadyana Pujaatmaja. Edisi Kesepuluh.
Jakarta: PT Indeks Kelompok Gramedia.

Rahmila, 2012. Pengaruh Kepemimpinan, Motivasi dan Stres Kerja Terhadap Kinerja Karyawan Pada Bank Syariah Mandiri Kantor Cabang Makassar. Jurnal Analisis, Vol.1, No.1.

(2006). Perilaku organisasi. Edisi kesepuluh. Jakarta: PT Indeks Kelompok Gramedia.

Sukadji. (2001). Motivasi dalam masyarakat. Jakarta :Gramedia

Swalhi, A., Zgoulli, S., \& Hofaidhllaoui, M. (2017). The influence of organizational justice on job performance: The mediating effect of affective commitment. Journal of Management Development, 36(4), 542-559. 10.1108/JMD-11- 2015-0162

Wibowo . (2014) . Manajemen kinerja. Edisi Keempat . Jakarta : Rajawali Pers

Wihler, A. et al. (2015). Political Skill, Leadership, and Performance : The Role of Vision Identification and Articulation by Accepted for publication in Handbook of Organizational Politics : Looking Back and to the Future Eran Vigoda-Gadot and Amos Drory (Eds .)', pp. 5-25.

Winkel, W. S. (2004). Psikologi pendidikan dan evaluasi belajar. Jakarta: PT. Gramedia Pustaka Utama.

Wright, T. A., Cropanzano, R., \& Bonett, D. G. (2007). ) The moderating role of employee positive well being on the relation between job satisfaction and job performance. Journal of Occupational Health Psychology.,12 (2), 93-104.

Yozgat, U, Yurtkoru S., Bilginoglu E. (2013). Job stress and job performance among employees in public sector in Istanbul: examining the moderating role of emotional intelligence. Procedia-Social and Behavioral Sciences. 75:518-524.

Zafar, Q, Ayesha, A, Tayyab H, Toqeer I. (2015). The Influence of Job Stress on Employees Performance in Pakistan. American Journal o Social Science Research. Vol.1 No.4:221-225. 